Article

\title{
Effects of Polybenzoxazine on Shape Memory Properties of Polyurethanes with Amorphous and Crystalline Soft Segments
}

\section{Senlong Gu and Sadhan Jana *}

Department of Polymer Engineering, University of Akron, 250 Forge Street, Akron, OH 44325-0301, USA; E-Mail: sg91@zips.uakron.edu

* Author to whom correspondence should be addressed; E-Mail: janas@uakron.edu; Tel.: +1-330-972-8293; Fax: +1-330-972-3406.

Received: 27 February 2014 in revised form: 13 March 2014 / Accepted: 24 March 2014 / Published: 1 April 2014

\begin{abstract}
This paper evaluates the role of minor component polybenzoxazine (PB) on shape-memory properties of polyurethanes (PU) with glassy and crystalline soft segments. The polymer compounds were prepared in two steps. In the first step, benzoxazine, polyurethane pre-polymer, and chain extender butanediol (BD) were mixed into a solution followed by chain-extension of the pre-polymer with $\mathrm{BD}$. In the second step, benzoxazine was polymerized at $180{ }^{\circ} \mathrm{C}$ for $3 \mathrm{~h}$ to obtain shape memory polymer compounds. The atomic force microscopy images revealed that the PB-phase formed uniform dispersions in PU. The presence of PB-phase induced shape-memory behavior in non-shape memory PU with amorphous soft segment and significantly improved the values of shape fixity, recovery ratio, and recovery stress in shape memory polyurethane with crystalline soft segment.
\end{abstract}

Keywords: shape memory; polyurethane; polybenzoxazine

\section{Introduction}

Shape-memory polymers (SMPs) gained considerable attention from academia and industry as smart materials due to their low cost, good processability, and light weight [1-6]. They have the capability of fixing in one or multiple temporary shapes, and return to the original shape upon application of an external stimulus [2,4,7-13]. Shape-memory polyurethanes (SMPUs) attract particular interest because of their biocompatibility, biodegradability, inexpensive raw materials, and 
high potential for commercialization [14-19]. The excellent properties of SMPUs are derived from the microphase-separated structures resulting from the thermodynamic incompatibility between the blocks of hard and soft segments [20]. Note that SMPs should possess two structural entities to exhibit shape-memory effects (SME): (1) a mechanically strong cross-linked network structure to fix the permanent shape, and (2) a reversible domain to undergo shape fixation and shape recovery. In thermoplastic PUs, the physical cross-links ramified by hydrogen bonds between the hard segments meet the first requirement. The second requirement is met by soft segment domains. Most SMPUs rely on thermal transition of the soft segment phase for shape-memory actuation. The transition temperature can either be a glass transition $\left(T_{\mathrm{g}}\right)$ or melting temperature $\left(T_{\mathrm{m}}\right)$, respectively, for SMPU with amorphous and crystalline soft segments [21-26].

SMPUs suffer from several shortcomings [2,5], such as low recovery stress, slow recovery rate, and low values of shape fixity and recovery ratio. The shape memory performance improves with the introduction of nanofillers, such as multiwall carbon nanotubes and nanofibers [27-33], functionalized graphene, and nanoclay [34,35], silicon carbide [36] and with organic components, such as poly(oxyethylene) [37], poly(vinyl chloride) [38], and soy protein [39]. These additives contribute to improvements in shape-memory properties via physical interactions with PU chains. Specifically, the extent of phase separation of the hard segment domains in PU reduces significantly in the presence of physically interacting filler particles [40]. This study considered polymeric chemical additive polybenzoxazine (PB) for augmentation of shape memory properties. It was anticipated that PB would produce physical interactions via hydrogen bonds, form covalent chemical bonds with PU chains, and act as fixed phase due to much higher glass transition temperature than PU.

$\mathrm{PB}$ is a thermosetting resin with high $T_{\mathrm{g}}$, near-zero volume shrinkage upon curing, low water absorption, and high mechanical integrity [41-44]. The monomer of this resin, benzoxazine (BA-a), is synthesized by a solventless method from bisphenol-A, aniline, and paraformaldehyde. The benzoxazine is polymerized into PB by thermally-induced ring opening polymerization via cationic bond cleavage at elevated temperatures. Studies on PB-urethane polymer alloys have focused on improvement of the properties of PB by incorporating urethanes [44-48]. Numan and Jana [48] reported synthesis and properties of shape-memory polyurethane-polybenzoxazine compounds where the focus was to obtain further increases in shape-memory performance by introduction of PB. It was established that PB provided additional hard domains and led to large enhancements in shape recovery force, speed of shape recovery, and greater recovery ratio than the base case shape memory PU with amorphous soft segment.

The present work is divided into two parts. In the first part, the SME was induced at room temperature in a non-shape memory PU with amorphous soft segment. The non-shape memory PU had a soft segment with glass transition temperature close to room temperature and had lower hard segment contents (HSC) than what was considered by Erden and Jana [48]. In this context, one should note that the shape recovery ratio is strongly dependent on the hard segment content $[18,49]$. In this work, the minor component PB was expected to add the following attributes: (1) increase the $T_{\mathrm{g}}$ and increase the modulus and (2) integrate the hard domain structures by covalent bonding between PB and PU chains. The second part of the study considered compounds of PB and shape memory PU with crystalline soft segments and evaluated how inclusion of PB improved the shape memory properties. Note that PB domains can hinder phase separation of urethane hard segments [48] and the inclusion of nanoparticles 
has detrimental effects on crystallization of PU soft domains [35,36,40]. In view of these, this study also focused on in the influence of PB domains on the crystallinity of PU soft domains.

\section{Experimental Section}

\subsection{Materials}

SMPU with amorphous soft-segment was synthesized from 4,4 -methylenebis (phenyl isocyanate) (MDI), poly(tetramethylene)glycol (PTMG), and chain extender 1,4-butanediol (BD). SMPU with crystalline soft-segment was synthesized from MDI, poly(caprolactone)diol (PCL), and BD. MDI of molecular weight $\left(\mathrm{M}_{\mathrm{w}}\right) \approx 250 \mathrm{~g} \mathrm{~mol}^{-1}$, PTMG of $\mathrm{M}_{\mathrm{w}} \approx 650 \mathrm{~g} \mathrm{~mol}^{-1}$, and BD of $\mathrm{M}_{\mathrm{w}} \approx 90 \mathrm{~g} \mathrm{~mol}^{-1}$ were purchased from Sigma-Aldrich (St. Louis, MO, USA). Poly(caprolactone)diol of $\mathrm{M}_{\mathrm{w}} \approx 4000 \mathrm{~g} \mathrm{~mol}^{-1}$ was obtained from Perstorp (Warrington, UK). The chain extension reaction was catalyzed by dibutyltin dilaurate (DABCO T120, Air Products Inc. Allentown, PA, USA). Benzoxazine monomer was synthesized from bisphenol-A of $\mathrm{M}_{\mathrm{w}} \approx 228.3 \mathrm{~g} \mathrm{~mol}^{-1}$, aniline of $\mathrm{M}_{\mathrm{w}} \approx 93.13 \mathrm{~g} \mathrm{~mol}^{-1}$, and paraformaldehyde. The materials were purchased from Sigma-Aldrich.

\subsection{Preparation Method}

\subsubsection{Benzoxazine Monomer}

Benzoxazine monomer was synthesized using a method reported by Ishida [50]. Bisphenol A, aniline, and paraformaldehyde in molar ratio 1:2:4 were added in a preheated beaker and mixed at $110{ }^{\circ} \mathrm{C}$ for $20 \mathrm{~min}$. The product was a yellowish viscous liquid that solidified quickly under room temperature. The solid was pulverized and stored in a cool place.

Table 1. Molar ratio of ingredients, hard segment content (HSC), and weight percent of benzoxazine in SMPU with amorphous soft-segment.

\begin{tabular}{ccccccc}
\hline Sample & $\begin{array}{c}\text { MDI } \\
\text { (mole) }\end{array}$ & $\begin{array}{c}\text { PTMG } \\
\text { (mole) }\end{array}$ & $\begin{array}{c}\text { BD } \\
\text { (mole) }\end{array}$ & $\begin{array}{c}\text { Benzoxazine } \\
\text { (mole) }\end{array}$ & $\begin{array}{c}\text { HSC } \\
\mathbf{( \% )}\end{array}$ & $\begin{array}{c}\text { PB } \\
\text { (wt\%) }\end{array}$ \\
\hline gPU & 3 & 1 & 2 & 0 & 58.9 & 0 \\
gPUPB2 & 3 & 1 & 1.8 & 0.2 & 61.1 & 6.4 \\
gPUPB4 & 3 & 1 & 1.6 & 0.4 & 63.0 & 12.1 \\
\hline
\end{tabular}

\subsubsection{SMPU with Amorphous Soft-Segment}

SMPU was synthesized by a two-step polymerization method. First, the prepolymer was synthesized from MDI and PTMG in the molar ratio 3:1 at $75^{\circ} \mathrm{C}$ for $2.5 \mathrm{~h}$ under nitrogen. Second, the chain extension was carried out in Brabender Plasticorder mixer (Model EPL 7752, C.W. Brabender, South Hackensack, NJ, USA). The prepolymer was mixed with BD and DABCO T120 at $80{ }^{\circ} \mathrm{C}$ for 3 min.

The SMPU-benzoxazine compounds were prepared in Brabender mixer. Figure 1 shows the timeline of the procedure. PU prepolymer was added to the mixer at $80{ }^{\circ} \mathrm{C}$ and mixed for $30 \mathrm{~s}$ before adding the benzoxazine powder of prescribed molar ratio (Table 1). The ingredients were mixed for 
$60 \mathrm{~s}$ to make sure that the mixture became clear. BD with catalyst was added into Brabender mixer to carry out the chain extension at $80^{\circ} \mathrm{C}$ for $90 \mathrm{~s}$.

\subsubsection{SMPU with Crystalline Soft-Segment}

In the first step of the two-step synthesis method, prepolymer of SMPU was synthesized from MDI and PCL in the molar ratio 5:1. This bulk polymerization was conducted at $80{ }^{\circ} \mathrm{C}$ for $2.5 \mathrm{~h}$ under nitrogen. Second, chain extension in Brabender mixer was carried out by mixing prepolymer, BD, and catalyst at $90{ }^{\circ} \mathrm{C}$ for approximately $5 \mathrm{~min}$. The SMPU-benzoxazine compounds were prepared at $90{ }^{\circ} \mathrm{C}$ in Brabender mixer (Figure 1). Table 2 presents the molar ratio of ingredients in these samples.

Figure 1. Timeline for preparation of Shape-Memory Polyurethanes (SMPU)-benzoxazine compounds. The set temperature of Brabender Mixer was respectively $80{ }^{\circ} \mathrm{C}$ and $90{ }^{\circ} \mathrm{C}$ for PU with amorphous and crystalline soft-segment.

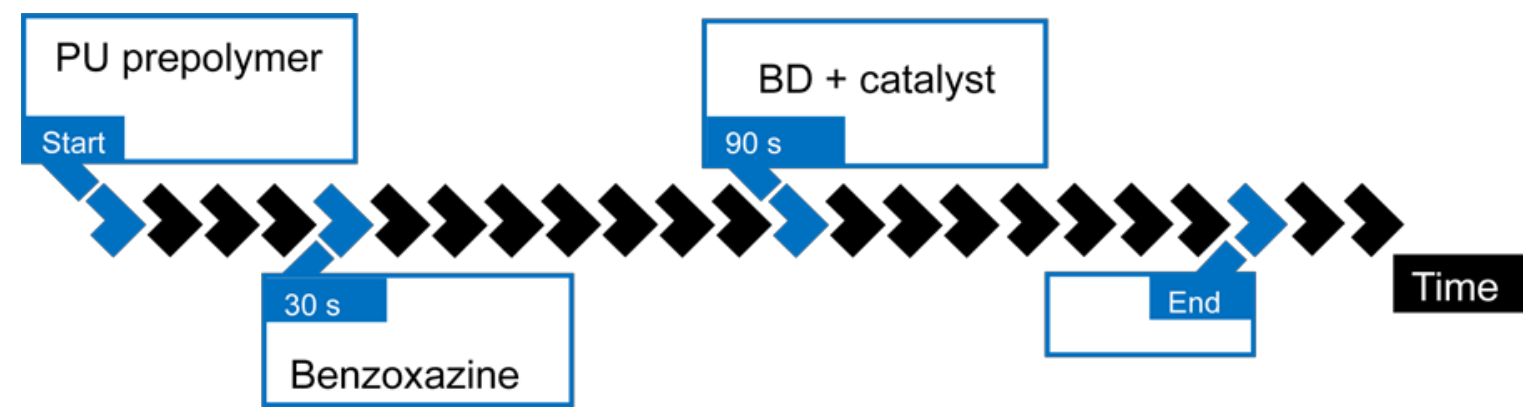

Table 2. Molar ratio of ingredients, hard segment content (HSC) and weight percent of benzoxazine in SMPU with crystalline soft-segment.

\begin{tabular}{ccccccc}
\hline Sample & $\begin{array}{c}\text { MDI } \\
\text { (mole) }\end{array}$ & $\begin{array}{c}\text { PCL } \\
\text { (mole) }\end{array}$ & $\begin{array}{c}\text { BD } \\
\text { (mole) }\end{array}$ & $\begin{array}{c}\text { Benzoxazine } \\
\text { (mole) }\end{array}$ & $\begin{array}{c}\text { HSC } \\
\mathbf{( \% )}\end{array}$ & $\begin{array}{c}\text { PB } \\
\text { (wt\%) }\end{array}$ \\
\hline mPU & 5 & 1 & 4 & 0 & 28.7 & 0 \\
mPUPB5 & 5 & 1 & 3.5 & 0.5 & 31.4 & 4.6 \\
mPUPB10 & 5 & 1 & 3 & 1.0 & 33.9 & 8.8 \\
\hline
\end{tabular}

\subsubsection{Preparation of SMPU-PB Compounds}

The solid products obtained from Brabender mixer was dried under vacuum at $40{ }^{\circ} \mathrm{C}$ before converting them into films (thickness $\approx 0.5 \mathrm{~mm}$ ) by using compression molding machine at a pressure of 21-28 MPa. The temperature and time for compression molding were respectively $180{ }^{\circ} \mathrm{C}$ and $10 \mathrm{~min}$. Note that the ring-opening polymerization of benzoxazine is typically achieved at temperatures $160-220^{\circ} \mathrm{C}$. In this case, the films were kept in vacuum oven at $180{ }^{\circ} \mathrm{C}$ for $3 \mathrm{~h}$ to carry out the polymerization of benzoxazine. The films of pristine PUs were also kept in the oven for the same duration to obtain the same heat history. 


\subsection{Characterization}

\subsubsection{Thermal Properties}

SMPU with amorphous soft-segment. The melting transition of hard segments was determined from differential scanning calorimetry (DSC) using a TA Instrument differential calorimeter (Model: Q200, TA Instruments Inc., Pittsburgh, PA, USA). The thermal scans were carried out with a heating rate of $10^{\circ} \mathrm{C} \mathrm{min}^{-1}$ from room temperature to $275^{\circ} \mathrm{C}$ under nitrogen atmosphere.

SMPU with crystalline soft-segment. The melting temperature $\left(T_{\mathrm{m}}\right)$ of soft and hard segments was obtained from DSC. The samples were first equilibrated at $20^{\circ} \mathrm{C}$ and then heated at $10^{\circ} \mathrm{C} \mathrm{min}{ }^{-1}$ to $250{ }^{\circ} \mathrm{C}$ under nitrogen atmosphere.

\subsubsection{Thermo-Mechanical Characterization}

The thermo-mechanical properties were evaluated by conducting experiments in a 'multi-frequency, strain' mode in a TA Instrument, dynamical mechanical analyzer (DMA; Model: Q800, TA Instruments Inc., Pittsburgh, PA, USA) at a frequency of $1 \mathrm{~Hz}$. The samples were cut so that the length-to-width ratio mounted between the grips was around 2; the thickness of specimen was varied from $0.3-0.5 \mathrm{~mm}$. The rectangular samples were heated at a rate of $4{ }^{\circ} \mathrm{C} \mathrm{min}{ }^{-1}$ from $-50-150{ }^{\circ} \mathrm{C}$. The values of storage modulus and shift angle were recorded as functions of temperature.

\subsubsection{Surface Morphology}

Tapping-mode atomic force microscopy (AFM; Model: MMAFM-2, Digital Instruments Inc., Tonawanda, NY, USA) was used to obtain the phase information from the images of smooth surfaces of sample specimens. The phase angle was $30^{\circ}$ for SMPU specimens with amorphous soft-segments and $120^{\circ}$ for SMPU specimens with crystalline soft-segment. These produced enough contrast between the mechanical properties of soft-segment, urethane hard-segment, and PB domains. The light spots on the phase images imply hard domains and the dark ones imply soft domains.

\subsubsection{Fourier Transform Infra-Red Analysis}

Perkin Elmer attenuated total reflectance (ATR; Model: Nicolet 380, Thermo Electron corporation, Marietta, OH, USA) and Fourier transform infrared (FTIR; Model: Nicolet 380, Thermo Electron Corporation, Marietta, OH, USA) spectroscopy methods with a resolution of $4 \mathrm{~cm}^{-1}$ in the range of $400-4000 \mathrm{~cm}^{-1}$ were used to determine the extent of hydrogen-bonded and free urethane carbonyl groups.

\subsubsection{Shape-Memory Properties}

Shape-memory properties were characterized using DMA and Instron tensile testing machine (Model: 5567, Instron, Norwood, MA, USA) with temperature-controlled chamber. A typical shape-memory cycle consists of four successive steps. (1) Deformation: The rectangular sample of original length $L_{0}$ was heated to its transformation temperature ( $\left.T_{\text {trans }}\right)$ before a force was imposed on it and elongated to a length $L_{\mathrm{s}}$. The values of $T_{\text {trans }}$ of SMPU with amorphous soft-segment are listed in Table 3. The value of $T_{\text {trans }}$ for SMPU with crystalline soft-segment was $60{ }^{\circ} \mathrm{C}$. (2) Cooling: The 
specimen with the load applied was cooled down to room temperature. (3) Fixing: The tensile load was released and an instantaneous shrinkage of the length occurred from $L_{\mathrm{s}}$ to $L_{\mathrm{f}}$. (4) Recovery: The deformed sample was heated to its $T_{\text {trans }}$ to allow for the length to recover to $L$. The lengths of specimens in different stages are used to define shape fixity $(S F)$ and recovery ratio $(R R)$, as follows:

$$
\begin{aligned}
& S F=\frac{L_{f}-L_{o}}{L_{s}-L_{o}} \times 100 \% \\
& R R=\frac{L_{f}-L}{L_{f}-L_{o}} \times 100 \%
\end{aligned}
$$

A value of $S F$ close to $100 \%$ indicates no shrinkage after the load is removed, while a $100 \% R R$ implies that the specimen is able to recover its original length. The values of shape recovery stress $(R S ; \sigma)$ were also determined by DMA. In this case, the stretched specimen was fixed between the grips and the stress $\sigma$ required to keep the sample from recovery was monitored as a function of temperature and time.

Table 3. Transition temperature of SMPU with amorphous soft-segment.

\begin{tabular}{cc}
\hline Sample & $\mathbf{T}_{\text {trans }}\left({ }^{\circ} \mathbf{C}\right)$ \\
\hline gPU & 54 \\
gPUPB2 & 92 \\
gPUPU4 & 110 \\
\hline
\end{tabular}

\section{Results and Discussion}

\subsection{SMPU with Amorphous Soft-Segment}

\subsubsection{Glass Transition and Melting}

The value of soft segment $T_{\mathrm{g}}$ is needed to determine a suitable value of $T_{\text {trans }}$, such that $T_{\text {trans }}>T_{\mathrm{g}}$. Figure 2 shows the DSC traces of three specimens. These samples were heated from room temperature to $250{ }^{\circ} \mathrm{C}$ with a heating rate of $10{ }^{\circ} \mathrm{C} \mathrm{min}^{-1}$. The curve for gPU (Table 1) shows two weak zones of glass transition with $T_{\mathrm{g}}$ at around $49{ }^{\circ} \mathrm{C}$ and $95{ }^{\circ} \mathrm{C}$, attributed respectively to soft- and hard-segment rich domains. However, these two transitions do not appear in DSC traces of compounds gPUPB2 and gPUPB4, indicating that the $\mathrm{PB}$ domains probably promoted mixing between the hard and soft-segment phases as was seen in another study [47]. Note that the $T_{\mathrm{g}}$ of $\mathrm{PB}$ is around $170{ }^{\circ} \mathrm{C}$ [42]. Thus, phase mixing of $\mathrm{PB}$ with the soft and hard domains should increase their respective $T_{\mathrm{g}}$ values. The DSC traces of PU-PB compounds (gPUPB2 and gPUPB4) in Figure 2 show heat flow curves with small slope, implying that accurate values of $T_{\mathrm{g}}$ of PU-PB compounds cannot be computed from these DSC traces. 
Figure 2. DSC traces of PU with amorphous soft-segment and its compounds with $\mathrm{PB}$. The compounds were cured at $180^{\circ} \mathrm{C}$. Scan rate was $10^{\circ} \mathrm{C} \mathrm{min}^{-1}$.

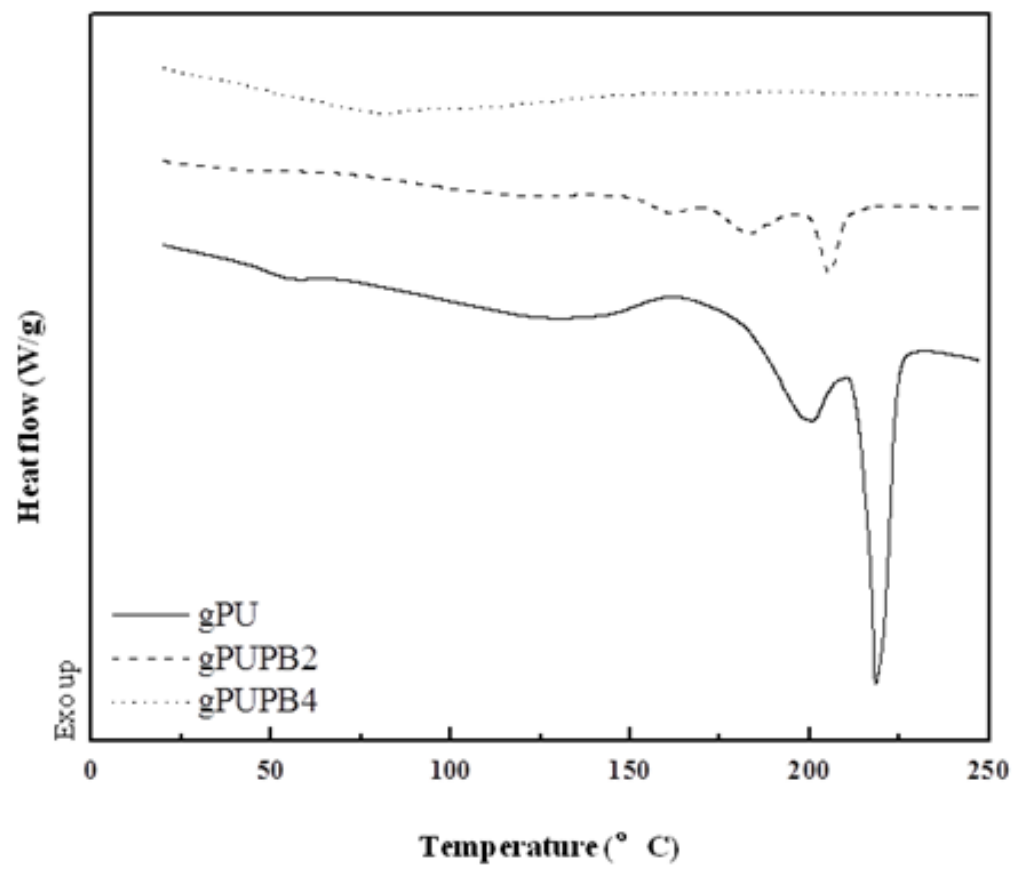

The DSC traces in Figure 2, however, show melting transitions of the crystalline domains. Sample gPU exhibits two melting peaks with a total heat of fusion of $26.88 \mathrm{~J} \mathrm{~g}^{-1}$, with the peak temperature respectively $200{ }^{\circ} \mathrm{C}$ and $218{ }^{\circ} \mathrm{C}$. The melting peak due to crystalline hard segment also appeared in the DSC trace of gPUPB2 compound with peak temperatures of $161{ }^{\circ} \mathrm{C}, 183^{\circ} \mathrm{C}$, and $205^{\circ} \mathrm{C}$ and the total heat of melting of $13.36 \mathrm{~J} \mathrm{~g}^{-1}$. The DSC trace of gPUPBZ4 compound, however, does not show the melting peak due to hard segment. The reduction of heat of melting observed in gPUPB2 compound and the absence of melting peaks in gPUPBZ4 compound together indicate that hard segment crystallization was hindered due to the presence of $\mathrm{PB}$ in these compounds.

\subsubsection{Phase Mixing and PB Domain Size}

Figure 3 shows the phase images of SMPU from atomic force microscopy scans. In Figure 3a, the dark and bright areas represent respectively the soft and hard domains of SMPU. Figure 3b,c also shows some extremely bright spots; these can be identified as the aggregates of PB. The typical size of $\mathrm{PB}$ domains inferred from Figure $3 \mathrm{~b}$ is $150 \mathrm{~nm}$, which grew to a size of $250 \mathrm{~nm}$ in Figure 3c due to an increase of the PB content from 6-12 wt\%.

In view of the phase mixing seen in Figure 3, one can envisage that the PB domains are connected to PU chains by hydrogen bonding and covalent linkages. The hydrogen bonds form between the phenolic - $\mathrm{OH}$ groups on PB chains and the soft and hard segments of PU. The covalent bonds link the $\mathrm{PB}$ and $\mathrm{PU}$ chains via chemical reactions between the $-\mathrm{NCO}$ groups of $\mathrm{PU}$ and the phenolic $-\mathrm{OH}$ groups of PB chains. A comparison of the ${ }^{13} \mathrm{C}$ NMR spectra of gPU and gPUPB4 presented in Figure 4 confirms the existence of covalent bonds between PU and PB chains. A new peak at around $146 \mathrm{ppm}$ appearing in the NMR spectra of gPUPB4 matches with the ${ }^{13} \mathrm{C}$ NMR signature of the carbon on the benzene ring of PB and adjacent to the oxygen connected with PU chains. The unique carbon atoms 
are labeled in the chemical structure of PU-PB chains and presented in Figure 4. However, the peak at 146 ppm is relatively weak, apparently due to small concentration of PB chains in the system. This is in good agreement with the earlier reports [45-47,51]. The covalent bond formation between PU chains and $\mathrm{PB}$ and the AFM phase morphology in Figure 3 can now explain the absence of soft-segment glass transition in DSC traces and the reduction of heat of fusion of the hard segments in PU-PB compounds.

Figure 3. AFM phase images of samples (a) gPU. (b) gPUPB2. (c) gPUPB4. The contrast covers phase variations in $0^{\circ}-30^{\circ}$ range.

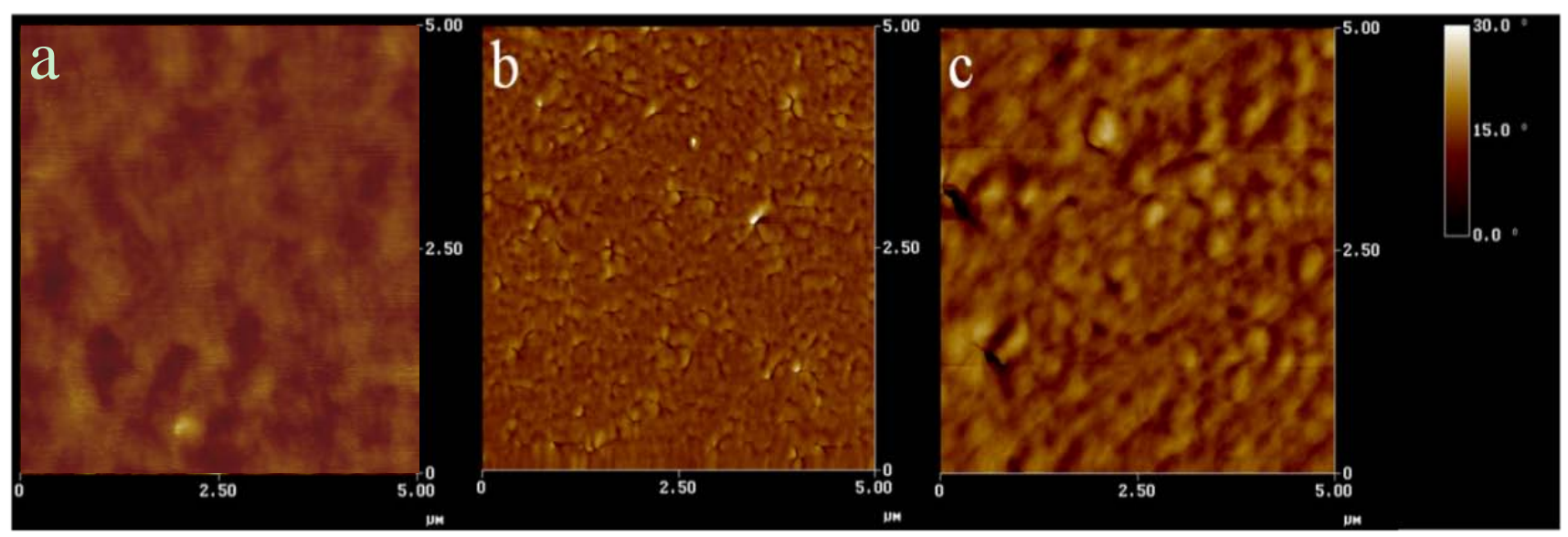

Figure 4. ${ }^{13} \mathrm{C}$ NMR spectra of gPU and gPUPB4.

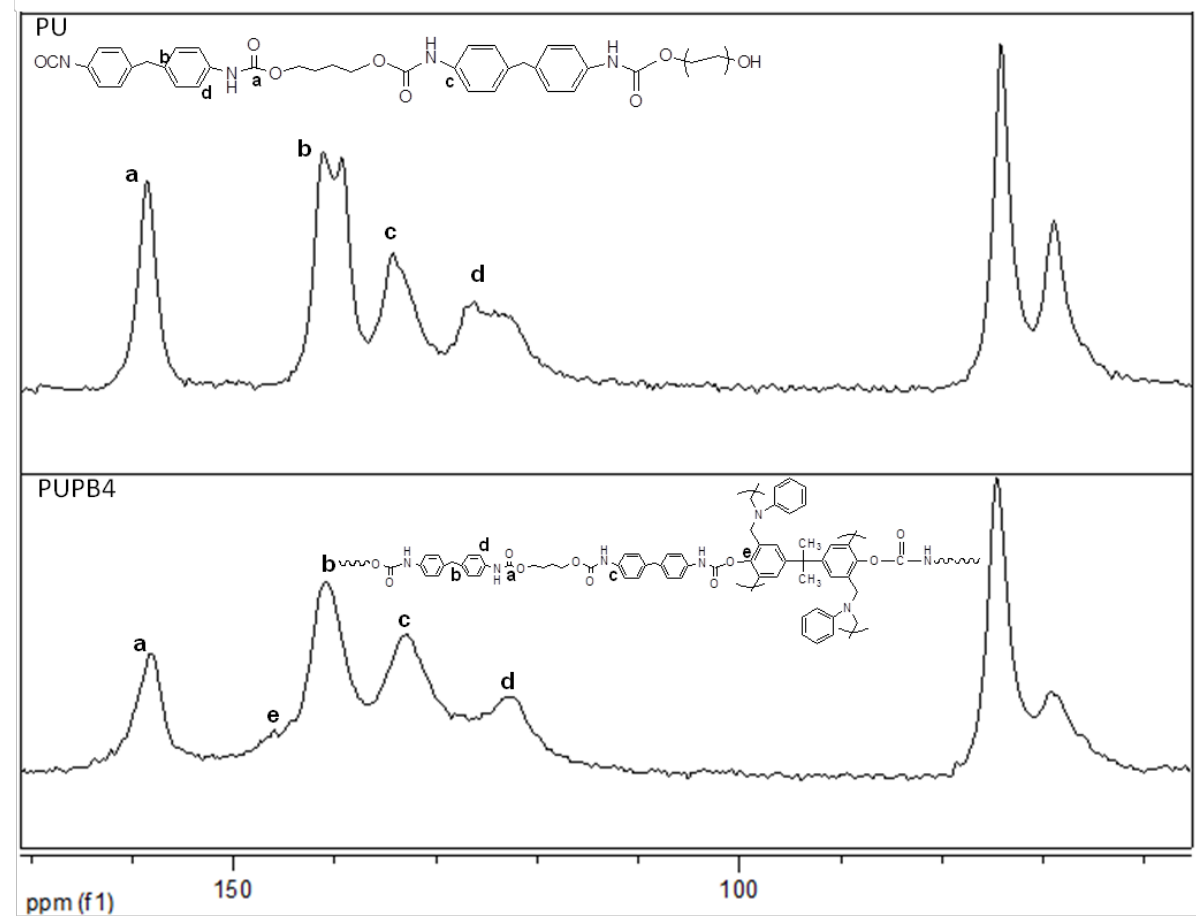


Further evidence of the reduction of microphase separation was obtained from FT-IR data. The values of hydrogen bonding index $(\alpha)$ were calculated from Equation (3) and the values are listed in Table 4.

$$
\alpha \equiv\left(\mathrm{A}_{\mathrm{aHCO}}+\mathrm{A}_{\mathrm{cHCO}}\right) /\left(\mathrm{A}_{\mathrm{aHCO}}+\mathrm{A}_{\mathrm{cHCO}}+\mathrm{A}_{\mathrm{FCO}}\right)
$$

The areas under the peaks at $1730 \mathrm{~cm}^{-1}$ due to free CO $\left(A_{\mathrm{FCO}}\right)$, at $1710 \mathrm{~cm}^{-1}$ due to hydrogen-bonded $\mathrm{CO}\left(\mathrm{A}_{\mathrm{aHCO}}\right)$ in amorphous hard domains and at $1703 \mathrm{~cm}^{-1}$ due to hydrogen-bonded $\mathrm{CO}\left(\mathrm{A}_{\mathrm{cHCO}}\right)$ in crystalline hard domains were used to calculate the hydrogen bonding index, $\alpha$. Two conclusions can be drawn from the data in Table 4: (1) the extent of phase separation in SMPU reduced due to the incorporation of $\mathrm{PB}$ and (2) the reduction of phase separation is due to loss of crystalline urethane hard segment domains.

Table 4. Hydrogen bonding index $(\alpha)$ of SMPU with amorphous soft segment.

\begin{tabular}{lcccc}
\hline Sample & $\mathbf{A}_{\text {снсо }}$ & $\mathbf{A}_{\text {aнсо }}$ & A $_{\text {FCo }}$ & $\boldsymbol{\alpha}$ \\
\hline gPU & 5.2 & N/A & 3.0 & 0.63 \\
gPUPB2 & 0.8 & 2.2 & 7.0 & 0.30 \\
gPUPB4 & 0.7 & 2.0 & 6.5 & 0.29 \\
\hline
\end{tabular}

\subsubsection{Dynamic Mechanical Properties}

The values of glass transition temperature can be inferred from $\tan \delta$ vs. temperature curves, as listed in Table 3. The tan $\delta$ vs. temperature traces in Figure 5a reveal that all materials exhibit a single peak of $\tan \delta$, indicating the $T_{\mathrm{g}}$ of soft domains of gPU, gPUPB2, and gPUPB4, respectively, at $14^{\circ}$, $52^{\circ}$, and $60{ }^{\circ} \mathrm{C}$. One can attribute such increases in $T_{\mathrm{g}}$ to mixing of PB domains.

Figure $5 \mathrm{~b}$ shows the values of storage modulus as a function of temperature. The larger storage modulus of gPU than gPUPB2 and gPUPB4 above the glass transition temperature of the soft segment is attributed to greater quantity of crystalline PU hard segment. The values of storage modulus $\left(E^{\prime}\right)$ at $\left(T_{\mathrm{g}}-20^{\circ} \mathrm{C}\right)$ and $\left(T_{\mathrm{g}}+20^{\circ} \mathrm{C}\right)$ and the ratio of $E^{\prime}\left(T_{\mathrm{g}}-20^{\circ} \mathrm{C}\right)$ and $E^{\prime}\left(T_{\mathrm{g}}+20^{\circ} \mathrm{C}\right)$ are listed in Table 5. The modulus ratios were 4 of gPU, 102 of gPUPB2, and 156 of gPUPB4. It was earlier proposed that a large difference of storage modulus above and below the glass transition temperature and a sharp glass to rubber transition are prerequisites for efficient shape recovery from the deformed state [52]. Generally, the ratio of modulus in glassy and rubbery states of 20 indicates good shape memory performance. In view of this, the values of $E^{\prime}\left(T_{\mathrm{g}}-20^{\circ} \mathrm{C}\right) / E^{\prime}\left(T_{\mathrm{g}}+20^{\circ} \mathrm{C}\right)$ reported in Table 5 imply the following: (1) The unmodified PU with amorphous soft-segment considered in this work cannot exhibit shape recovery as it cannot hold the temporary shape due to $T_{\mathrm{g}}$ value lower than the room temperature. (2) The two PU-PB compounds prepared in this work should show excellent shape-memory properties, as will be seen below. 
Figure 5. (A) Loss tangent $(\tan \delta)$. (B) Storage modulus $\left(E^{\prime}\right)$ as a function of temperature. Heating rate, $4{ }^{\circ} \mathrm{C} \mathrm{min}^{-1}$; frequency, $1 \mathrm{~Hz}$.; scan between $-50{ }^{\circ} \mathrm{C}$ and $150{ }^{\circ} \mathrm{C}$.
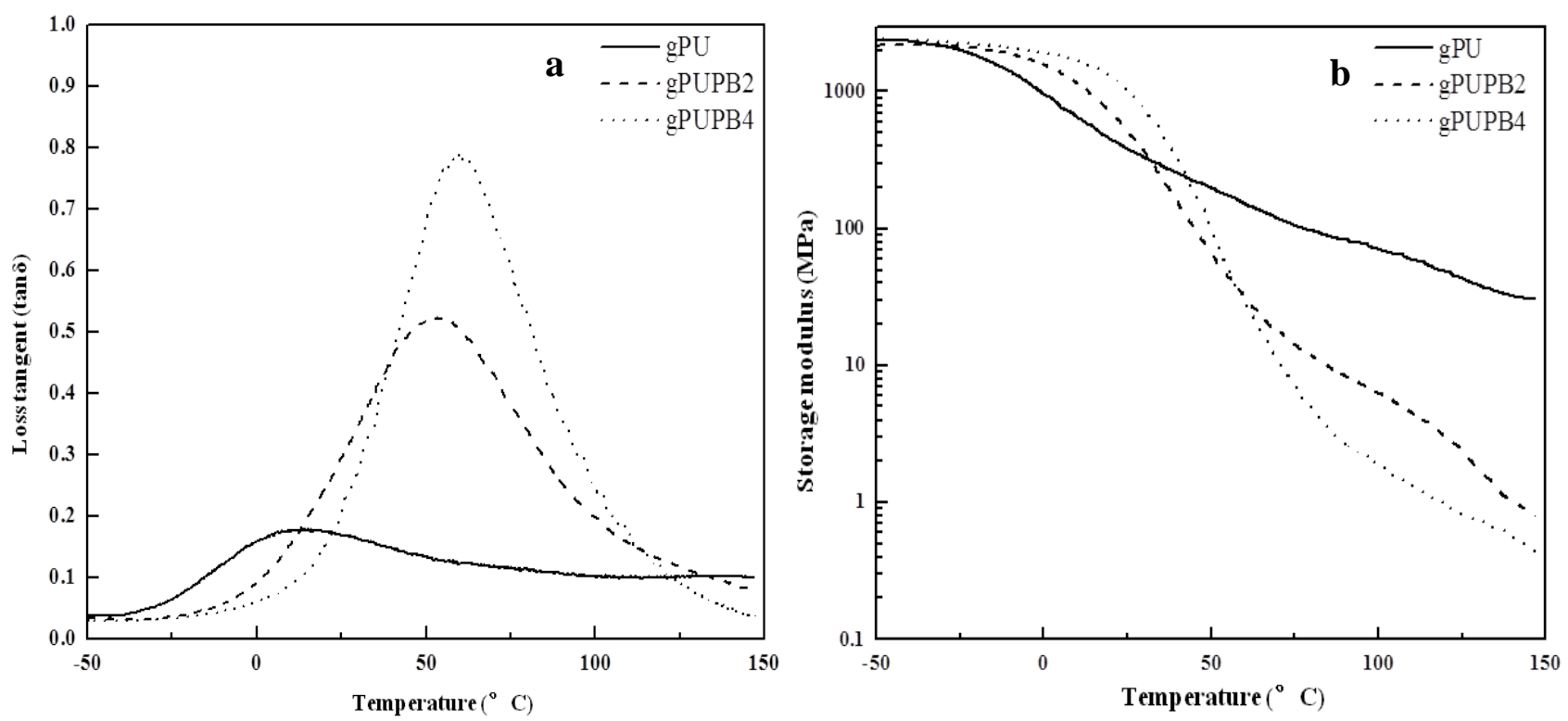

Table 5. The values of storage modulus at $T_{\mathrm{g}}-20^{\circ} \mathrm{C}$ and $T_{\mathrm{g}}+20^{\circ} \mathrm{C}$.

\begin{tabular}{lccc}
\hline Sample & $E^{\prime}\left(\boldsymbol{T}_{\mathrm{g}}-\mathbf{2 0}{ }^{\circ} \mathbf{C}\right)(\mathbf{M P a})$ & $E^{\prime}\left(\boldsymbol{T}_{\mathrm{g}}+\mathbf{2 0}{ }^{\circ} \mathbf{C}\right)(\mathbf{M P a})$ & $E^{\prime}\left(T_{\mathrm{g}}-\mathbf{2 0}{ }^{\circ} \mathrm{C}\right) / E^{\prime}\left(T_{\mathrm{g}}+\mathbf{2 0}{ }^{\circ} \mathrm{C}\right)$ \\
\hline gPU & 1100 & 292 & 4 \\
gPUPB2 & 818 & 8 & 102 \\
gPUPB4 & 313 & 2 & 156 \\
\hline
\end{tabular}

\subsubsection{Shape-Memory Properties}

Shape fixity. A rectangular specimen was first stretched at $T_{\text {trans }}$ to $30 \%$ its original length and then cooled down to $T_{\mathrm{g}}-40^{\circ} \mathrm{C}$ at a cooling rate of $5^{\circ} \mathrm{C} \mathrm{min}{ }^{-1}$ to obtain the temporary shape. The specimen dimension was measured at $\left(T_{\mathrm{g}}-40\right)^{\circ} \mathrm{C}$. The values of shape fixity are as follows: $97.2 \%$ for gPU, 95.3\% for gPUPB2, and $92.8 \%$ for gPUPB4. Shape fixity refers to the unconstrained recovery of SMPs after the stretching load was removed. A value less than $100 \%$ indicates that an instantaneous shrinkage of the stretched polymer chains cannot preserve the imposed strain. Recall that the values of $T_{\mathrm{g}}$ of samples obtained from DMA were 14,57 and $70{ }^{\circ} \mathrm{C}$, respectively, for gPU, gPUPB2 and gPUPB4. Accordingly, the temporary shape was fixed at $-26,17$ and $30{ }^{\circ} \mathrm{C}$, respectively, for gPU, gPUPB2, and gPUPB4. Of the three materials, the compounds gPUPB2 and gPUPB4 were able to retain the deformed shapes at room temperature.

Recovery ratio. Figure 6 presents the shape recovery values of samples as a function of time. The test began with the material kept at the fixing temperature, e.g., at $-26,17$ and $30{ }^{\circ} \mathrm{C}$, respectively, for gPU, gPUPB2, and gPUPB4 and continued to $T_{\text {trans }}$ of each sample with a heating rate of $5{ }^{\circ} \mathrm{C} \min ^{-1}$ and kept isothermal for a period of $20 \mathrm{~min}$. The maximum values of recovery ratio of samples are respectively $60 \%$ for gPU, $82 \%$ for gPUPB2, and 93\% for gPUPB4. It is evident that incorporation of 
PB led to obvious enhancement in shape recovery ratio. The PB domains acted as the hard phase in the compounds with PU and strengthened the polymer networks, keeping the permanent shape of specimen via physical and chemical interactions with PU chains. The rate of recovery can also be inferred from Figure 6. The higher the values of modulus ratio $E^{\prime}\left(T_{\mathrm{g}}-20{ }^{\circ} \mathrm{C}\right) / E^{\prime}\left(T_{\mathrm{g}}+20{ }^{\circ} \mathrm{C}\right)$, the higher is the recovery rate as is apparent from the greater slope seen in Figure 6. The specimen gPUPB4 shows the fastest recovery rate among three samples considered in this work.

Figure 6. Shape recovery ratio as a function of time. Samples were heated from fixing temperature to respective $T_{\text {trans }}$ at a heating rate of $5{ }^{\circ} \mathrm{C} \min ^{-1}$ and kept isothermal for $20 \mathrm{~min}$.

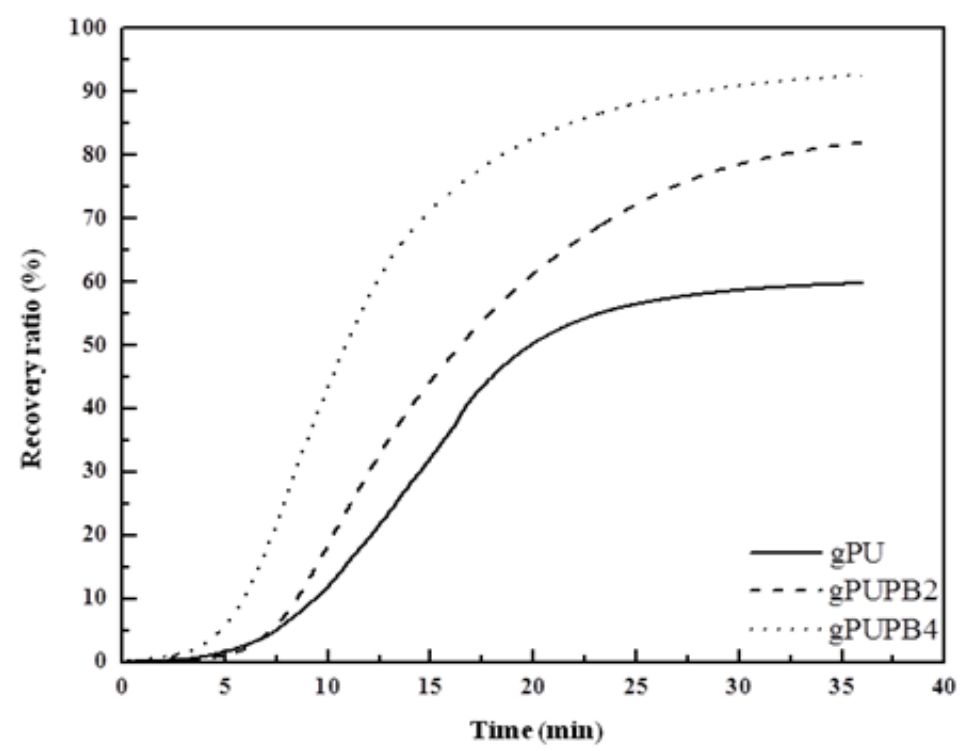

\subsection{SMPU with Crystalline Soft Segment}

\subsubsection{Thermal Transitions}

Figure 7A,B shows DSC traces of samples heated from room temperature to $250{ }^{\circ} \mathrm{C}$ before and after $100 \%$ elongation, respectively. Table 6 summarizes the values of melting temperature $\left(T_{\mathrm{m}}\right)$ and heat of fusion $(\Delta H)$ of crystalline soft domains of pristine PU and PU-PB compounds. Table 6 reveals that both $T_{\mathrm{m}}$ and $\Delta H$ of unstretched specimens decreased with an increase of PB content. One plausible explanation is that the hard PB aggregates mixed well with the PCL domains in the as-prepared compounds and consequently restricted the crystallization of PCL chains. However, such reduction is not observed in the case of stretched samples. Note that the samples were stretched after the crystals were all melted and then cooled to room temperature. In this context, some degree of strain-induced crystallinity of PCL domains quite possibly compensated for the loss due to interactions of PCL chains with PB domains. The DSC traces also show melting of hard domains. Note that the hard segment content of pristine PU in Table 2 was only 28.7\%. In Figure 7B, the weak peaks were observed for all three traces and the peak temperature and the heat of melting were found to be, respectively, $215{ }^{\circ} \mathrm{C}$ and $6.4 \mathrm{~J} \mathrm{~g}^{-1}$, $206{ }^{\circ} \mathrm{C}$ and $5.8 \mathrm{~J} \mathrm{~g}^{-1}$ and $199{ }^{\circ} \mathrm{C}$ and $2.3 \mathrm{~J} \mathrm{~g}^{-1}$. 
Figure 7. DSC traces of (A) unstretched SMPU and its compounds; (B) stretched SMPU and its compounds. Scan rate was $10{ }^{\circ} \mathrm{C} \mathrm{min}^{-1}$. The base SMPU contained crystalline soft-segment.
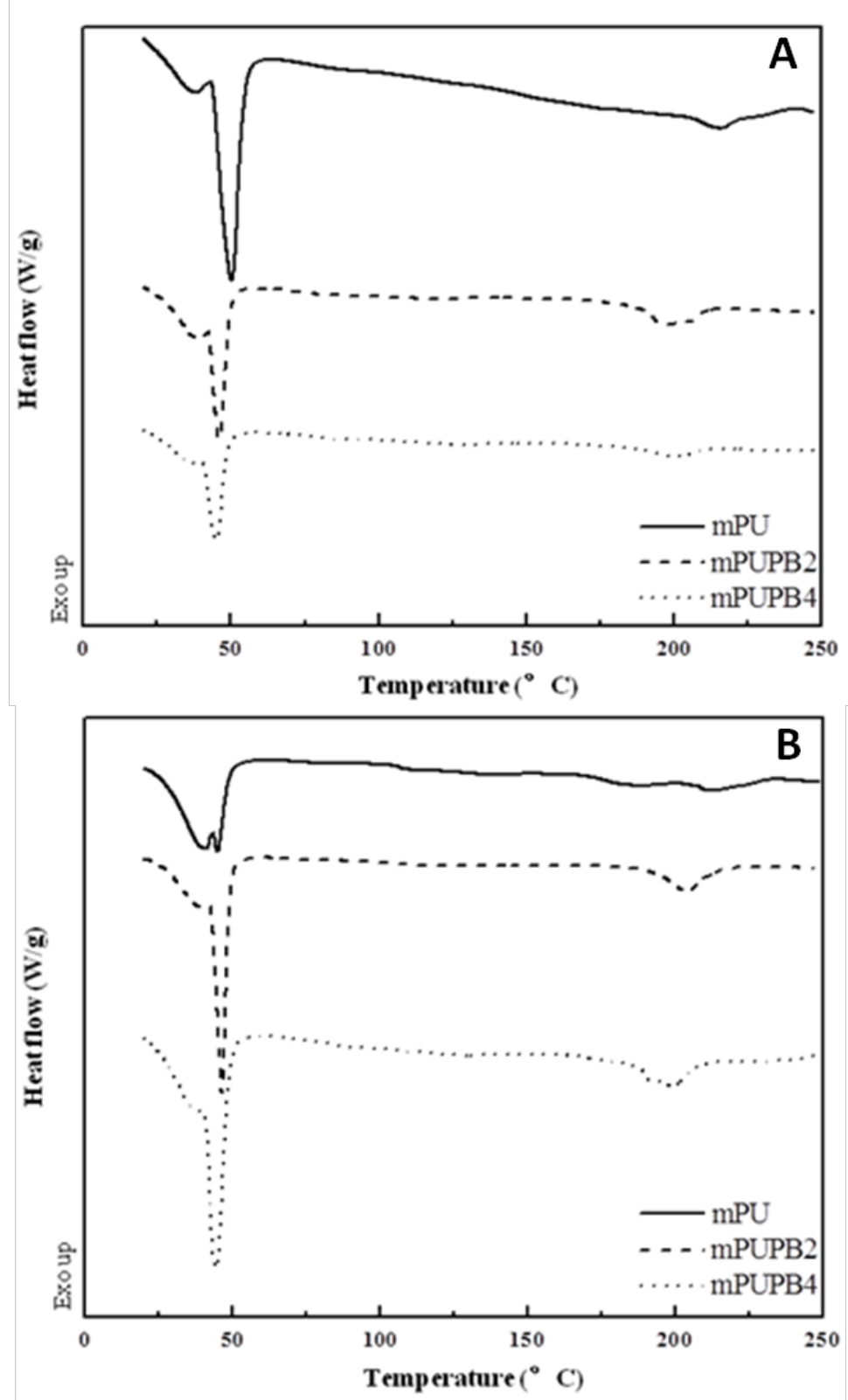

Table 6. Comparison of melting temperature and heat of fusion of crystalline soft segment before and after $100 \%$ elongation.

\begin{tabular}{lcccc}
\hline \multirow{2}{*}{ Sample } & \multicolumn{2}{c}{ Melting temperature $\left({ }^{\circ} \mathbf{C}\right)$} & \multicolumn{2}{c}{ Heat of fusion $\left(\mathbf{J ~ g}^{-\mathbf{1}}\right)$} \\
\cline { 2 - 5 } & Before stretching & After stretching & Before stretching & After stretching \\
\hline mPU & 50 & 45 & 33.3 & 19.9 \\
mPUPB5 & 46 & 46 & 25.1 & 19.3 \\
mPUPB10 & 45 & 45 & 18.1 & 20.8 \\
\hline
\end{tabular}




\subsubsection{Phase Mixing}

The AFM phase images of SMPU with crystalline soft-segment are presented in Figure 8. The brighter regions seen in Figure 8b,c in comparison to Figure 8a are attributed to harder PB domains. It is also seen that an increase of PB content from 4.6-8.8 wt\% resulted in larger sized PB domains.

Figure 8. AFM phase images of samples (a) mPU, (b) mPUPB5, (c) mPUPB10. The contrast covers phase variations in the $0^{\circ}-120^{\circ}$ range.

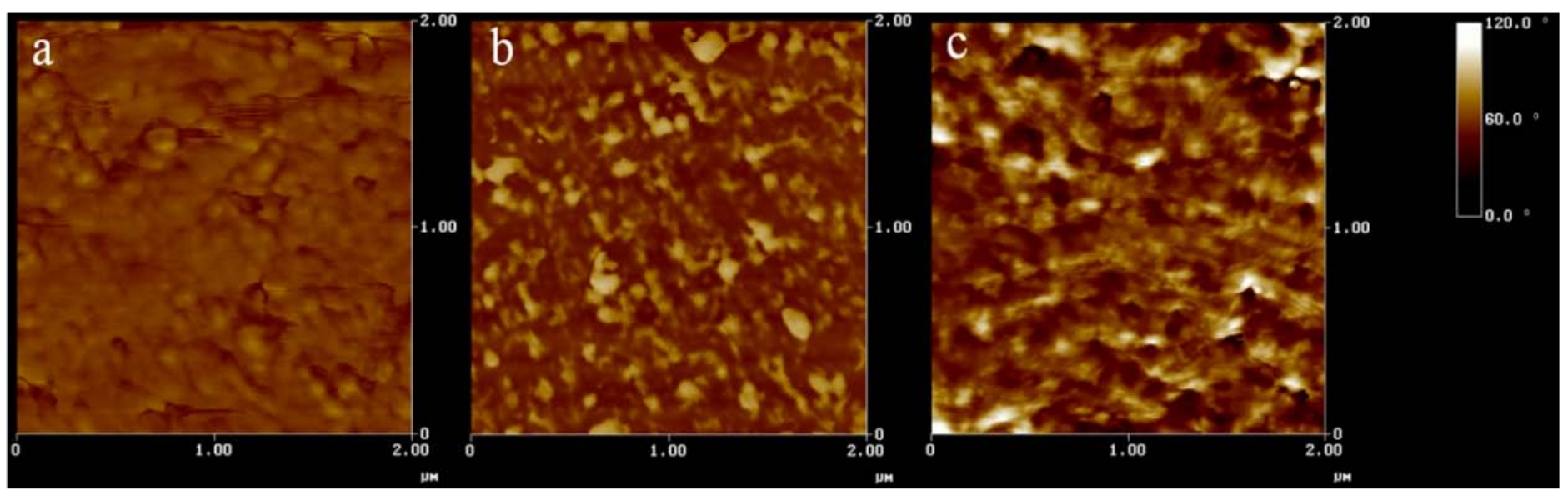

\subsubsection{Shape-Memory Properties}

Shape fixity. The shape fixity of SMPU specimen with crystalline soft-segment was measured and the values are as follows: $95.8 \%$ for mPU, 95.8\% for mPUPB5, and 96.2\% for mPUPB10. It is evident that the shape fixity value does not depend on PB content. This is not surprising, as PCL crystalline domains are responsible for fixing the shape and the DSC data of stretched specimens showed earlier that PB content has no influence on PCL crystallinity. The small loss in shape fixity in this case can be attributed to immediate recovery of the amorphous polyurethane chains once the stretching load is released. It is noted that the $T_{\mathrm{g}}$ of PCL segments was around $-50{ }^{\circ} \mathrm{C}$, which indicates that the amorphous soft segment phase was in rubbery state at room temperature.

Recovery ratio. The sample specimen stretched earlier to $100 \%$ of original length and cooled down to room temperature to fix the shape were heated again from room temperature to $80{ }^{\circ} \mathrm{C}$ with a heating rate of $10{ }^{\circ} \mathrm{C} \min ^{-1}$ and the specimen length was measured as function of time. Figure 9 presents the values of recovery ratio as function of time. The specimens began recovery almost at the same time after a delay of $\sim 2.5 \mathrm{~min}$. It is seen that the recovery rate increased with an increase of temperature. The maximum values of recovery ratio were found to be $94.1 \%$ for $\mathrm{mPU}, 96.6 \%$ for mPUPB5, and 98.0\% for mPUPB10, indicating that the recovery ratio of PU-PB compounds increases slightly with the PB-content.

Recovery stress. Figure 10 shows the representative plots of stress vs. time as sample specimen were heated in a DMA set up. In this case, the stress needed to keep the original length of the specimen fixed at a constant value was measured as function of temperature. It is apparent that recovery began at around $40^{\circ} \mathrm{C}$ by which time some of the crystalline soft domains melted. As revealed in Figure 10, the stress increased with temperature and reached a maximum at around $65{ }^{\circ} \mathrm{C}$. The maximum recovery 
stress was found to be 1.0 MPa for mPU, 1.4 MPa for mPUPB5, and 1.8 MPa for mPUPB10, which are less than the stress imposed on the materials during tensile deformation, e.g., $1.1 \pm 0.07 \mathrm{MPa}$ for mPU, $1.7 \pm 0.04 \mathrm{MPa}$ for mPUPB5, and $2.2 \pm 0.03$ for mPUPB10. The lesser values of recovery stress compared to the stress imposed during tensile deformation can be attributed to stress relaxation during cooling of the deformed specimens and heating in stress recovery experiments. This data indicates that an increase of $80 \%$ in recovery stress can be obtained with 8.8 wt\% PB. Such large increases in recovery stress was also observed in SMPU system with amorphous soft segment [48].

Figure 9. Shape recovery ratio as a function of time. Samples were heated to $80{ }^{\circ} \mathrm{C}$ at a heating rate of $4{ }^{\circ} \mathrm{C} \mathrm{min}^{-1}$ and kept isothermal for $10 \mathrm{~min}$.

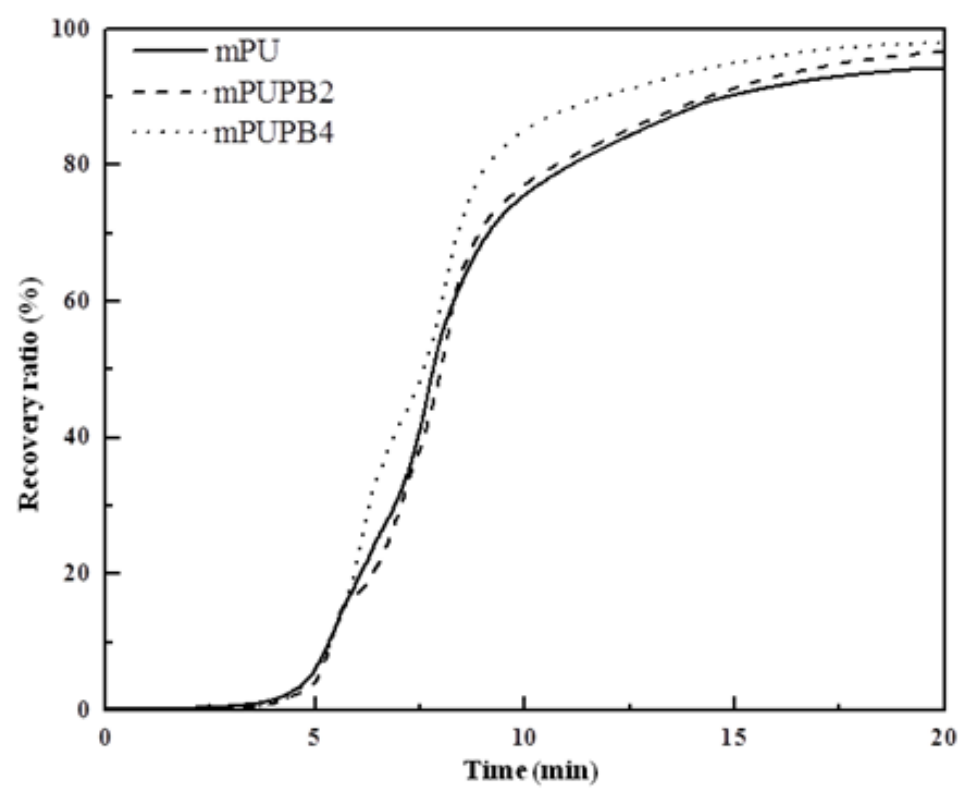

Figure 10. Shape recovery stress of SMPU with crystalline soft segment at $100 \%$ fixed strain during heating. Heating rate was $4{ }^{\circ} \mathrm{C} / \mathrm{min}$.

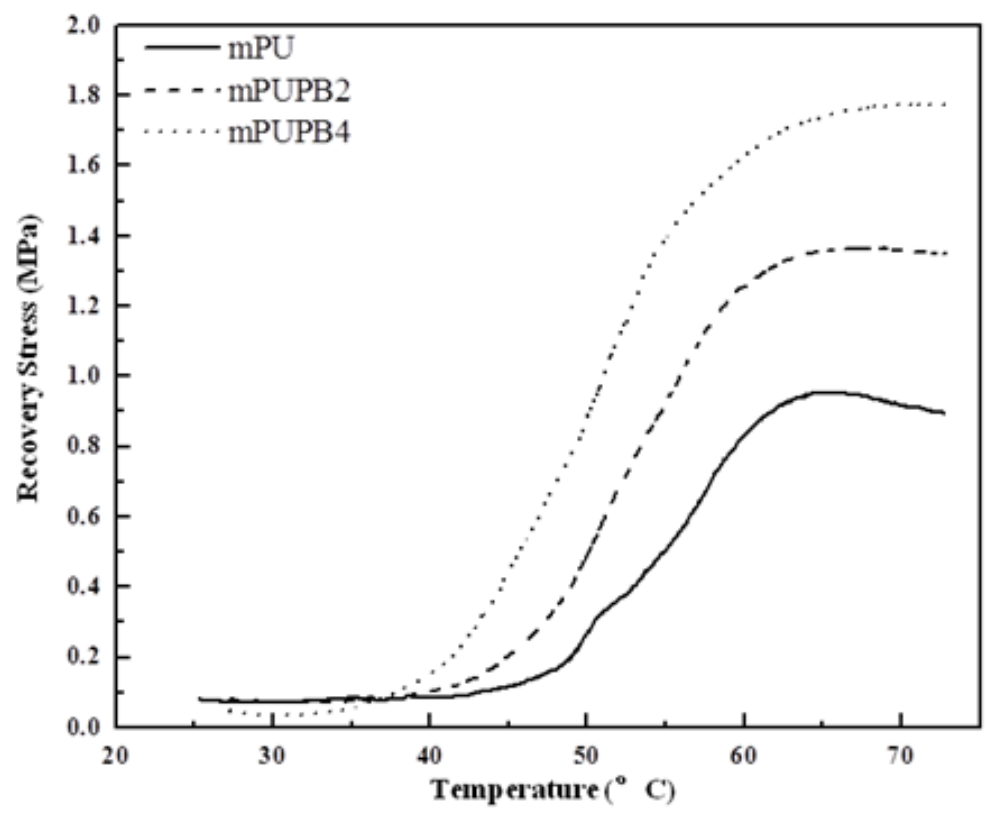




\section{Conclusions}

Several conclusions can be drawn from the study. First, polyurethanes with no shape memory properties at room temperature can be converted into shape memory materials by reactively blending with small quantities of PB. Specifically, the phase-mixing of PB with the amorphous soft segment in $\mathrm{PU}$ is able to bring up the glass transition temperature from $14{ }^{\circ} \mathrm{C}$ for the unmodified-PU to about $60{ }^{\circ} \mathrm{C}$. Thus, although the unmodified PU with amorphous soft-segment is not a shape memory polymer, its compounds with PB can exhibit good shape memory properties due to an increase of $T_{\mathrm{g}}$ to well above the room temperature and due to the additional fixed phase provided by the PB domains. Second, in the case of SMPUs with crystalline soft segment, the introduction of PB as additional fixed phase produces large increases in shape recovery force, although shape fixity does not change much. Third, the presence of PB domains causes significant improvement in shape recovery rate in polyurethanes.

\section{Conflicts of Interest}

The authors declare no conflict of interest.

\section{Acknowledgment}

Sadhan C. Jana acknowledges Hatsuo Ishida of Case Western Reserve University for introducing him to the chemistry of polybenzoxazine.

\section{References}

1. Wei, Z.G.; Sandstorm, R.; Miyazaki, S. Shape-memory materials and hybrid composites for smart systems: Part I Shape-memory materials. J. Mater. Sci. 1998, 33, 3743-3783.

2. Lendlein, A.; Kelch, S. Shape-memory polymers. Angew. Chem. Int. Ed. 2002, 41, 2034-2057.

3. Liu, C.; Qin, H.; Mather, P.T. Review of progress in shape-memory polymers. J. Mater. Chem. 2007, 17, 1543-1558.

4. Gunes, S.I.; Jana, S.C. Shape memory polymers and their nanocomposites: A review of science and technology of new multifunctional materials. J. Nanosci. Nanotech. 2008, 8, 1616-1637.

5. Liang, C.; Rogers, C.A.; Malafeew, E. Investigation of shape memory polymers and their hybrid composites. J. Intel. Mat. Syst. Str. 1997, 8, 380-386.

6. Mather, P.T.; Luo, X.; Rousseau, I.A. Shape memory polymer research. Annu. Rev. Mater. Res. 2009, 39, 445-471.

7. Luo, X.; Mather, P.T. Triple-shape polymeric composites (TSPCs). Adv. Funct. Mater. 2010, 20, 2649-2656.

8. Shao, Y.; Laviguer, C.; Zhu, X.X. Multishape memory effect of norbornene-based copolymers with cholic acid pendant groups. Macromolecules 2012, 45, 1924-1930.

9. Qin, H.; Mather, P.T. Combined One-Way and Two-Way Shape Memory in a Glass-Forming Nematic Network. Macromolecules 2009, 42, 273-280.

10. Xie, T.; Xiao, X.; Cheng, Y.-T. Revealing triple-shape memory effect by polymer bilayers. Macromol. Rapid Commun. 2009, 30, 1823-1827. 
11. Xie, T. Tunable polymer multi-shape memory effect. Nature 2010, 464, 267-270.

12. He, Z.; Satarkar, N.; Xie, T.; Cheng, Y.-T.; Hilt, J.Z. Remote controlled multishape polymer nanocomposites with selective radiofrequency actuations. Adv. Mater. 2011, 23, 3192-3196.

13. Liu, Y.; Lv, H.; Lan, X.; Leng, J.; Du, S. Review of electro-active shape-memory polymer composite. Comp. Sci. Tech. 2009, 69, 2064-2068.

14. Hayashi, S.; Kobayashi, K. Shape memory fibrous sheet and method of imparting shape memory property to fibrous sheet product. U.S. Patent 5,098,776, 24 March 1992.

15. Hayashi, S.; Kobayashi, K. Woven fabric made of shape memory polymer. U.S. Patent 5,128,197, 7 July 1992.

16. Gunatillake, P.A.; McCarthy, S.J.; Meijs, G.F.; Adhikari, R. Shape memory polyurethane or polyurethane-urea polymers. U.S. Patent 6,858,680, 22 February 2005.

17. Hayashi, S.; Ishibashi, A.; Ikenoue, T. Heat insulator made of shape memory polymer foam. U.S. Patent 5,093,384, 3 March 1992.

18. Lin, J.R.; Chen, L.W. Study on shape-memory behavior of polyether-based polyurethanes. I. Influence of hard-segment content. J. Appl. Polym. Sci. 1998, 69, 1563-1574.

19. Lin, J.R.; Chen, L.W. Study on shape-memory behavior of polyether-based polyurethanes. II. Influence of soft-segment molecular weight. J. Appl. Polym. Sci. 1998, 69, 1575-1586.

20. Murarka, M.R.; Deanin, R.D. Structure and Properties of One-Shot Thermoplastic Polyurethane Elastomers; University of Lowell: Lowell, MA, USA, 1983.

21. Kim, B.K.; Lee, S.Y. Polyurethanes having shape memory effects. Polymer 1996, 37, 5781-5793.

22. Li, F.; Zhang, X.; Hou, J.; Xu, M.; Ma, D.; Kim, B.K. Studies on Thermally Stimulated Shape Memory Effect of Segmented Polyurethanes. J. Appl. Polym. Sci. 1997, 64, 1511-1516.

23. Ji, F.L.; Hu, J.L.; Li, T.C.; Wong, Y.W. Morphology and shape memory effect of segmented polyurethanes. Part 1: With crystalline reversible phase. Polymer 2007, 48, 5133-5145.

24. Müller, W.W.; Pretsch, T. Hydrolytic aging of crystallizable shape memory poly(ester urethane): Effects on the thermo-mechanical properties and visco-elastic modeling. Eur. Polym. J. 2010, 46, 1745-1758.

25. Weng, S.; Xia, Z.; Chen, J.; Gong, L. Shape Memory Properties of Polycaprolactone-based Polyurethanes Prepared by Reactive Extrusion. J. Appl. Polym. Sci. 2013, 127, 748-759.

26. Bothe, M.; Emmerling, F.; Pretsch, T. Poly(ester urethane) with varying polyester chain length: Polymorphism and shape memory behavior. Macromol. Chem. Phys. 2013, 214, 2683-2693.

27. Jimenez, G.; Jana, S.C. Composites of carbon nanofibers and thermoplastic polyurethanes with shape-memory properties prepared by chaotic mixing. Polym. Eng. Sci. 2009, 49, 2020-2030.

28. Gunes, I.S.; Jimenez, G.; Jana, S.C. Carbonaceous fillers for shape memory actuation of polyurethane composites by resistive heating. Carbon 2009, 47, 981-997.

29. Koerner, H.; Price, G.; Pearce, N.A.; Alexander, M.; Vaia, R.A. Remotely actuated polymer nanocomposites-Stress-recovery of carbon-nanotube-filled thermoplastic elastomers. Nat. Mater. 2004, 3, 115-120.

30. Gall, K.; Mikulas, M.; Munshi, N.A.; Beavers, F.; Tupper, M. Carbon fiber reinforced shape memory polymer composites. J. Intel. Mat. Syst. Str. 2000, 11, 877-886.

31. Zhang, C.S.; Ni, Q.Q.; Fu, S.Y. Electromagnetic interference shielding effect of nanocomposites with carbon nanotube and shape memory polymer. Compos. Sci. Tech. 2007, 67, 2973-2980. 
32. Leng, J.; Lv, H.; Liu, Y.; Du, S. Synergic effect of carbon black and short carbon fiber on shape memory polymer actuation by electricity. J. Appl. Phys. 2008, 104, 104917:1-104917:4.

33. Meng, Q.; Hu, J.; Zhu, Y. Shape-memory polyurethane/multiwalled carbon nanotube fibers. J. App. Poly. Sci. 2007, 106, 837-848.

34. Pattanayak, A.; Jana, S.C. Thermoplastic polyurethane nanocomposites of reactive silicate clays: Effects of soft segments on properties. Polymer 2005, 46, 5183-5193.

35. Cao, F.; Jana, S.C. Nanoclay-tethered shape memory polyurethane nanocomposites. Polymer 2007, 48, 3790-3800.

36. Gunes, I.S.; Cao, F.; Jimenez, G.; Jana, S.C. Evaluation of nanoparticulate fillers for development of shape memory polyurethane nanocomposites. Polymer 2008, 49, 2223-2234.

37. Kurahashi, E.; Sugimoto, H.; Nakanishi, E.; Nagata, K.; Inomata, K. Shape memory properties of polyurethane/poly(oxyethylene) blends. Soft Matter 2012, 8, 496-503.

38. Jeong, H.M.; Song, J.H.; Lee, S.Y.; Kim, B.K. Miscibility and shape memory property of poly(vinyl chloride)/thermoplastic polyurethane blends. J. Mater. Sci. 2001, 36, 5457-5463.

39. Madbouly, S.A.; Lendlein, A. Degradable Polyurethane/Soy Protein Shape-Memory Polymer Blends Prepared Via Environmentally-Friendly Aqueous Dispersions. Macromol. Mater. Eng. 2012, 297, 1213-1224.

40. Gunes, I.S.; Pérez-Bolivar, C.; Cao, F.; Jimenez, G.A.; Anzenbacher, P.; Jana, S.C. Analysis of non-covalent interactions between the nanoparticulate fillers and the matrix polymer as applied to shape memory performance. J. Mater. Chem. 2010, 20, 3467-3474.

41. Ishida, H.; Allen, D.J. Physical and mechanical characterization of near-zero shrinkage polybenzoxazines. J. Polym. Sci. B Polym. Phys. 1996, 34, 1019-1030.

42. Ishida, H.; Sanders, D.P. Regioselectivity and solid-state structure of alkyl-substituted aromatic amine-based polybenzoxazines. Macromolecules 2000, 33, 8149-8157.

43. Takeichi, T.; Kawauchi, T.; Agag, T. High-performance polymer alloys of polybenzoxazine and bismaleimide. Polymer 2008, 49, 1173-1179.

44. Cui, Y.; Chen, Y.; Wang, X.; Tian, G,; Tang, X. Synthesis and characterization of polyurethane/polybenzoxazine-based interpenetrating polymer networks (IPNs). Polym. Int. 2003, 52, 1246-1248.

45. Rimdusit, S.; Pirstpindvong, S.; Tanthapanichakoon, W.; Damrongsakkul, S. Toughening of polybenzoxazine by alloying with urethane prepolymer and flexible epoxy: A comparative study. Poly. Eng. Sci. 2005, 45, 288-296.

46. Takechi, T.; Guo, Y. Preparation and properties of poly(urethane-benzoxazine)s based on monofunctional benzoxazine monomer. Polym. J. 2001, 33, 437-443.

47. Takechi, T.; Guo, Y.; Agag, T. Synthesis and characterization of poly(urethane-benzoxazine) films as novel type of polyurethane/phenolic resin composites. J. Polym. Sci. A Polym. Chem. 2000, 38, 4165-4176.

48. Erden, N.; Jana, S.C. Synthesis and Characterization of Shape-Memory PolyurethanePolybenzoxazine Compounds. Macromol. Chem. Phys. 2013, 214, 1225-1237.

49. Lee, S.H.; Kim, J.W.; Kim, B.K. Shape memory polyurethanes having crosslinks in soft and hard segments. Smart Mater. Struct. 2004, 13, 1345-1350. 
50. Ishida, H. Polybenzoxazine nanocomposites of clay and method for making same. U.S. Patent 6,323,270, 27 November 2001.

51. Ishida, H.; Ning, $X$. Phenolic materials via ring-opening polymerization: Synthesis and characterization of bisphenol-A based benzoxazines and their polymers. J. Polym. Sci. A Polym. Chem. 1994, 32, 1121-1129.

52. Hayashi, S. Properties and Applications of Polyurethane-Series Shape Memory Polymer. Int. Prog. Urethane 1993, 6, 90-115.

(C) 2014 by the authors; licensee MDPI, Basel, Switzerland. This article is an open access article distributed under the terms and conditions of the Creative Commons Attribution license (http://creativecommons.org/licenses/by/3.0/). 